\title{
A reassessment of the purported ankylosaurian dinosaur Bienosaurus lufengensis from the Lower Lufeng Formation of Yunnan, China
}

\author{
Thomas J. Raven, Paul M. Barrett, Xing Xu, and Susannah C.R. Maidment \\ Acta Palaeontologica Polonica 64 (2), 2019: 335-342 doi:https://doi.org/10.4202/app.00577.2018
}

The earliest definitive ornithischian dinosaurs are from the Early Jurassic and are rare components of early dinosaur faunas. The Lower Lufeng Formation (Hettangian-Sinemurian) of Yunnan Province, China, has yielded a diverse Early Jurassic terrestrial vertebrate fauna. This includes several incomplete specimens have been referred to Ornithischia, including the type specimen of the thyreophoran "Tatisaurus" and other generically indeterminate material. The highly fragmentary Lufeng ornithischian Bienosaurus lufengensis was described briefly in 2001 and identified as an ankylosaurian dinosaur. Recent studies have cast doubt on this hypothesis, however, and given that the referral of Bienosaurus to Ankylosauria would result in an extensive ghost-lineage extending between it and the first definitive eurypodans (ankylosaurs + stegosaurs) in the Middle Jurassic, the holotype specimen is re-examined and re-described. We identify Bienosaurus as a probable thyreophoran dinosaur, although the fragmentary nature of the material and the absence of autapomorphies means that the specimen should be regarded as a nomen dubium.

Key words: Dinosauria, Ornithischia, Thyreophora, anatomy, Jurassic, Lufeng Formation, Yunnan, China.

Thomas J. Raven [t.raven@nhm.ac.uk], Department of Earth Sciences, Natural History Museum, Cromwell Road, London SW7 5BD, UK; School of Environment and Technology, University of Brighton, Lewes Road, Brighton BN1 4JG, UK.

Paul M. Barrett [p.barrett@nhm.ac.uk] and Susannah C.R. Maidment [susannah.maidment@nhm.ac.uk ], Department of Earth Sciences, Natural History Museum, Cromwell Road, London SW7 5BD, UK. Xing Xu [xu.xing@ivpp.ac.cn], Key Laboratory of Evolutionary Systematics of Vertebrates, Institute of Vertebrate Paleontology \& Paleoanthopology, Chinese Academy of Sciences, 100044 Beijing, People's Republic of China; Center of Excellence in Life and Paleoenvironment, Chinese Academy of Sciences, 100044 Beijing, People's Republic of China. 
This is an open-access article distributed under the terms of the Creative Commons

Attribution License (for details please see creativecommons.org), which permits unrestricted use, distribution, and reproduction in any medium, provided the original author and source are credited.

\author{
For Full text $(285.0 \mathrm{kB})$ । \\ Far) Supplementary file $(180.6 \mathrm{kB})$
}

